\title{
MULTIPLE FAULTS DETECTION AND IDENTIFICATION OF THREE PHASE INDUCTION MOTOR USING ADVANCED SIGNAL PROCESSING TECHNIQUES
}

\author{
Majid Hussain \\ PhD Scholar IICT, Mehran University of Engineering and Technology. \\ Jamshoro, (Pakistan). \\ E-mail: majidhussain@quest.edu.pk ORCID: https://orcid.org/0000-0002-5581-1260
}

Rana Rizwan Ahmed

Department of Electronic Engineering, Mehran University of Engineering and Technology.

Jamshoro, (Pakistan).

E-mail: rizwan.ese@gmail.com ORCID: https://orcid.org/0000-0001-7449-3715

Imtiaz Hussain Kalwar

Department of Electrical Engineering, DHA SUFFA University.

Karachi, (Pakistan).

E-mail: imtiaz.hussain@dsu.edu.pk ORCID: https://orcid.org/0000-0002-7947-9178

Tayab Din Memon

NCRA CMS Lab, Mehran University of Engineering and Technology.

Jamshoro, (Pakistan).

E-mail: tayabdin82@gmail.com ORCID: https://orcid.org/0000-0001-8122-5647

Recepción: 07/09/2020 Aceptación: 02/10/2020 Publicación: 13/11/2020

Gitación sugerida Suggested citation

Hyder, M., y Ali, S. (2020). Multiple faults detection and identification of three phase induction motor using advanced signal processing techniques. 3C Tecnología. Glosas de innovación aplicadas a la pyme. Edición Especial, Noviembre 2020, 93-117. https:// doi.org/10.17993/3ctecno.2020.specialissue6.93-117 


\section{ABSTRACT}

In this paper, we have presented the multiple fault detection and identification system for three-phase induction motor. Fast Fourier Transform (FFT) is the most used signal processing technique that offers good frequency information but failing in providing time information and handling multiple faults identification with their occurrence time. FFT also fails to detect non-stationary condition of the signal and unable to convey sudden changes, start and end of the events, drifts and trends. To obtain simultaneous time frequency information and to deal with non-stationary signals Short Time Fourier Transform (STFT) is considered optimal technique that can clearly provide time and frequency information both. In this research work, the multiple fault detection and identification system is presented by employing Short Time Fourier Transform (STFT) signal processing technique. The proposed model is designed using current signature analysis method (CSAM) for three major faults including three phase supply imbalance, single phasing condition and breakage of rotor bars. The system is simulated in MATLAB/SIMULINK and simulation is performed based on healthy and unhealthy conditions of the motor. Comparative analysis between FFT and STFT, shows STFT as a promising approach.

\section{KEYWORDS}

Induction Motor, STFT, Matlab/Simulink, Current Signature Analysis, Power Supply Imbalance, Single Phasing, Broken Rotor Bar. 


\section{INTRODUCTION}

An Induction motor is the main source of mechanical power in almost every industry including sugar, fertilizer, packing, agriculture lands, domestic and commercial water supply schemes, water filtration, RO plant, locomotives etc. Apparently, induction motors are widely accepted in industrial processes as well due to its robustness, cost effectiveness, capability to operate in rough environment and less error chance (Pandey, Zope, \& Suralkar, 2012; Mortazavizadeh \& Mousavi, 2014; Nandi, Toliyat, \& Li, 2005; Soother \& Daudpoto, 2019). However, like other motors induction motor also faces several faults due to its operating environment and usage conditions. Most of the faults are due to load variations and improper power supply arrangements (Nandi et al., 2005; Soother, Daudpoto, \& Shaikh, 2018).

There are many electrical and mechanical faults related to both stator and rotor. Most described faults in the literature related to the rotor are bearing faults, broken rotor and end rings faults, and air gap eccentricity faults (Nandi et al., 2005; Mortazavizadeh \& Mousavi, 2014). The faults related to the stator are imbalance in the supply phase voltages, under or over voltage, single phasing condition, reverse phase sequence and inter turn short circuit fault etc. (Nandi et al., 2005; Mortazavizadeh \& Mousavi, 2014).

Presently much work is reported in this area to find, isolate and identify different types of the faults and avoid plant shutdown i.e., health of the motor is diagnosed by monitoring certain parameters. The parameter may be the vibration, torque, flux, temperature, current etc. (Mortazavizadeh \& Mousavi, 2014; El Bouchikhi, Choqueuse, \& Benbouzid, 2015). The condition monitoring makes it possible to detect any abnormal behavior in the motor at an early stage so that any big loss can be avoided (Gao, Cecati, \& Ding, 2015). After observing any abnormal condition, the necessary preventive maintenance strategies can be applied for the removal of faults Unlike corrective maintenance strategy in which correction applied after fault has gone through motor and motor operation is disturbed (Mal et al., 2020; Ujjan et al., 2020). In this case, motor may be seriously damaged and can cause unrecoverable loss to the plant.

Many researchers have been working in the field of condition monitoring for fault detection and identification using different fault diagnoses schemes including vibration, thermal, 
chemical and electrical (Nandi et al., 2005; Mortazavizadeh \& Mousavi, 2014; Gao etal., 2015). In vibration monitoring, faults are identified based on intensity of vibrations in healthy and unhealthy conditions. Vibration monitoring sometimes gives ambiguous result when there are fluctuations in the load so thermal monitoring is employed, in which temperature of the different sections of the machine is monitored and faults identified based on the sensors located at different sections on the motors. Thermal technique does not give good results when there are multiple faults in the motor and multiple temperature sensors requirement make it costly (Siddiqui et al., 2014).

Another technique previously used for fault detection is Air-Gap Torque monitored. In this technique motor torque is measured and non-zero frequency of the torque describes the faulty situation of the machine. Its main drawback is that there is no specific mathematical model available for fault signature (Gao et al., 2015). Stator power analyses is another useful technique used previously for unbalance fault detection in which spectral and AC components of the power signal are measured in all three phases. This technique fails to produce good results for low intensity faults (Sharma et al., 2015).

Nowadays, most used technique for condition monitoring of the motor is Motor Current Signature Analyses (MCSA). In MCSA stator current is continuously acquired and after applying a signal processing technique at current signal the frequency spectrum gives the knowledge about the health of the motor (Benbouzid, 2000; Zhongming \& Bin, 2000; Gao et al., 2015). The signal processing technique to be applied depends upon the type of the fault to be detected and nature of the fault. Some types of faults are low intensity in nature. Sometimes only information about frequency component of the signal is desired and, in some cases, both time and frequency information are required. So, it depends upon the fault which signal processing technique will be suitable for it (Nandi et al., 2005; Mortazavizadeh \& Mousavi, 2014). The most common signal processing techniques employed are FFT, Short time Fourier Transform (STFT), wavelet transform (WT), Hilbert-Huang transform (HHT) and Wigner-Ville Distribution (WVD) (Gao et al., 2015).

In Mehala and Dahiya (2008), Gusidó et al. (2008), and El Bouchikhi et al. (2015), authors have reported comparative study on different signal processing techniques and compared the results for broken rotor bar fault using FFT, STFT and wavelet transform. With variable 
FFT does not provides better results and misses to provide useful information like start and end of the event, changes in load etc. So, a new algorithm is proposed by using STFT and WT to achieve better results. It is further reported that each technique has advantages and disadvantages that depends upon the application and constraint for example performance, complexity, and desired results. It is not advisable to use STFT and WT for ordinary fault where only frequency information is needed. No doubt WT provides better results as compared to STFT but wavelet transform is complex in nature, as signal is divided into high and low frequency parts, therefore requires more calculations and computation time. It always remains an issue of selecting the basis for wavelets which matches with type of information is required. Interpreting the results of the wavelets also requires skill. STFT is the trade-off technique between FFT and WT. STFT provides better results for ordinary faults both in time and frequency domain with less effort. In Mirabbasi, Seifossadat, and Heidari (2009), authors have detected unbalance in supply voltages using FFT. In Liang et al. (2002), and Messaoudi and Sbita (2010), authors have detected unbalance supply fault and broken rotor bar fault using FFT. In Mehrjou et al. (2010), Shi et al. (2014), and Siddiqui and Giri (2012), wavelet transform is employed for broken rotor bar fault detection. In Da Silva, Povinelli, and Demerdash (2008), authors have used stator current envelope analyses for broken rotor bar fault and stator short circuit fault detection. In Çalış and Çakır (2008) zero crossing time technique for rotor bar fault is employed. In Haggag and Mageed (2013) authors have developed unity relation in which instantaneous voltage and its complement are squared in order to detect Single Phasing condition.

This research work presents the detection and identification of three types of motor faults using short time Fourier transform (STFT) namely a) Imbalance of supply Voltage b) Single Phasing of supply and c) broken rotor bars. It also presents the simultaneous detection of multiple faults.

Further this paper proceeds as follows. Section 2 describes possible reasons and impacts of faults in induction motor, Section 3 presents the simulation and mathematical model of induction motor with description of STFT, Section 4 presents comparative results of the proposed system in terms of FFT and STFT analysis, and Section 5 concludes the research. 


\section{CAUSES AND EFFECTS OF FAULTS OVER INDUCTION MOTOR}

In subsequent sections causes and effects of the faults over induction motor performance and stator current are discussed in detail that is followed by system modeling and simulations.

\subsection{IMBALANCE SUPPLY VOLTAGE}

There are several reasons for the imbalance in the power supply voltages. In Pakistan imbalance voltage condition is frequently faced in domestic, industrial and especially agriculture sector. The induction motors in the agriculture lands are located very far from the electrical substation. So, a very long distribution line and poor arrangement of electrical equipment causes too much voltage fluctuations and sometimes single phasing condition occurs, which can destroy the motor permanently. So, motor with applied imbalance voltage or in single phasing condition must not run for longer time to avoid any damage. Single phasing is most serious condition that induction motor faces and it can permanently damage the motor. The reasons for single phasing may include blowing of Line fuse, supply terminal loosing, connection of motor from a distribution transformer located very far, distribution transformer phase opening, Power supply wiring conductors may face unequal impedance (Mirabbasi et al., 2009; Lee, 1999).

The imbalance and single phasing condition cause several adverse effects on the performance of the induction motor. According to National Electrical Manufacturers Association (NEMA), for a better life of induction motor it should not be operated with more than 5\% unbalance in the supply (Quispe, Gonzalez, \& Aguado, 2004). Due to unbalance supply motor may experience negative and pulsating torque which may produce excessive noise. The imbalance will also increase the current imbalance in windings and temperature of the motor; this can reduce the life and efficiency of the motor.

\subsection{EFFECT OF SUPPLY VOLTAGES ON STATOR CURRENT}

The induction motor is operated at 3 phase supply with $50 \mathrm{~Hz}$ frequency. When motor is operating in normal condition the stator current spectrum will show only $50 \mathrm{~Hz}$ frequency.

If any type of the fault occurs, it causes sidebands near the main frequency. The frequency 
of the generated sidebands depends upon the type of the fault. Every specific fault will have its own current signature.

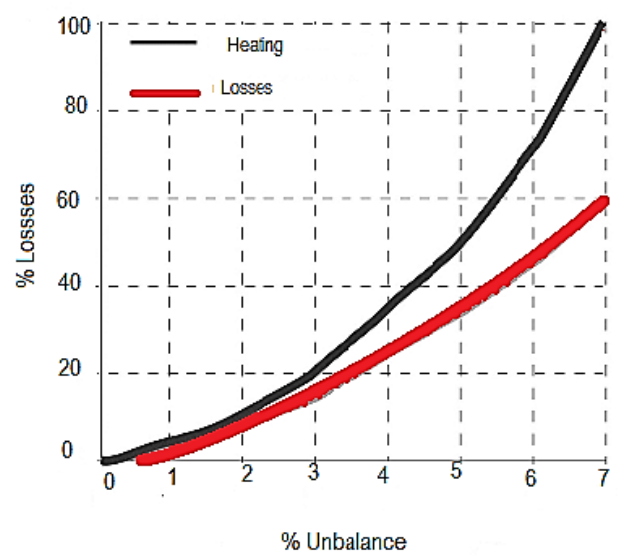

Figure 1. Increase in motor losses and heating due to unbalance voltage.

Figure 1 shows the impact of unbalance supply voltage on motor heating. The power supply unbalance fault will also introduce the sidebands frequencies upon occurrence of fault (Messaoudi \& Sbita, 2010).

$$
f u n v=(1+2 k) f s
$$

where, $\mathrm{k}=1,2,3, \ldots \ldots \ldots \mathrm{N}, \mathrm{f}_{\text {unv }}=$ unbalanced supply voltage, $\mathrm{fs}=$ frequency of supply voltage

\subsection{BROKEN ROTOR BAR FAULT}

The rotor of Squirrel cage induction motor as shown in Figure 2 is constructed of usually copper bars instead of windings and permanently short circuited with end rings. So, under certain load conditions these bars and end rings are cracked. 


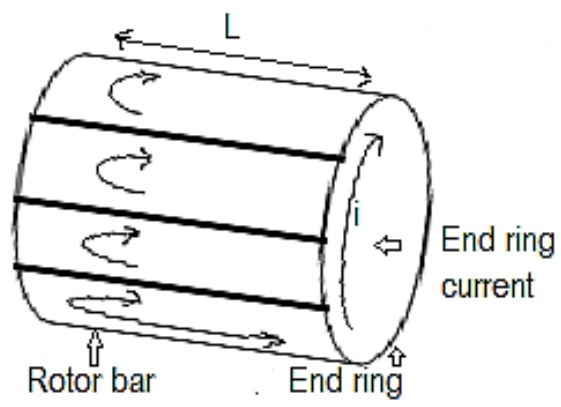

Figure 2. Rotor of induction motor.

Due to no. of reasons the cracks appear in the bars as well as at end rings. This may be due to thermal stress that causes overloading, magnetic stress caused by electromagnetic forces, due to electromagnetic force imbalance, vibration and noise cause stress on the Bars. Defect at manufacturing time causes residual stress. Dynamic stress as a result of shaft torque, centrifugal forces and cyclic stress has a negative impact on the rotor (Szabó, Dobai, \& Biró, 2004).

Under normal condition, current distribution in the rotor bars is uniform according to the load applied. Upon breakage of the bars, the resistance of the bars is increased and causes uneven distribution in current loops made by end rings and bars. So, if load is changed during induction motor operation the current distribution is greatly affected (Liang et al., 2014). This type of fault is load dependent.

\subsection{EFFECT OF FAULTY BROKEN BARS}

The change caused by broken rotor bars and end rings in the stator current will introduce new frequency components at the following frequencies (Messaoudi and Sbita, 2010):

$$
f b b=(1 \pm 2 k s) f s
$$

where, $k=1,2,3 \ldots, \mathcal{N}, f_{b b}$ : broken rotor bar frequency, $f s$ : electrical supply frequency, $p$ : number of pole pairs, $s$ : slip. 


\section{SYSTEM DESIGN AND IMPLEMENTATION}

The scope of the research work is limited to the fault detection and identification. This is achieved by continuously monitoring three phase stator current as shown in Figure 3, which depicts the implementation of fault diagnoses system for three phase induction motor.

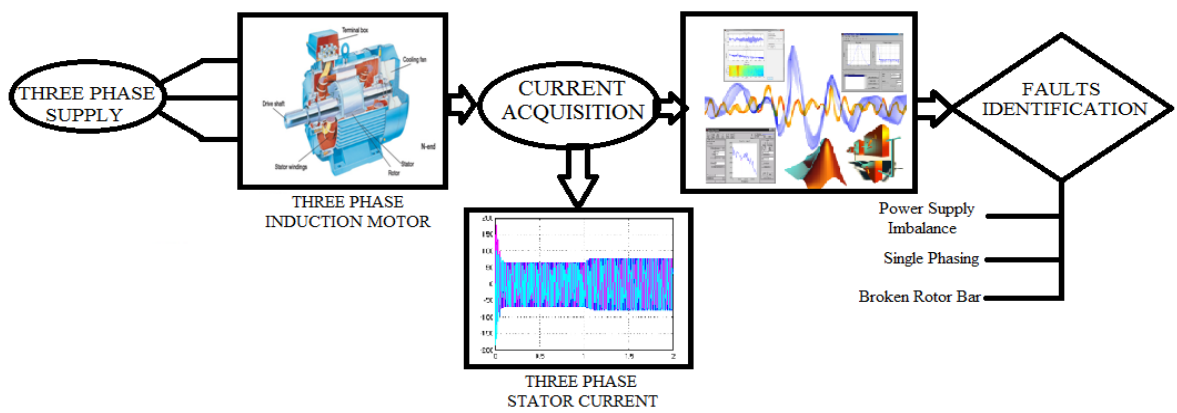

Figure 3. Multiple faults detection and identification system

Three phase supply is fed to the induction motor. Speed, Torque, and three phase stator current are the motor's outputs. As in MCSA, the individual phase stator current is taken as the monitoring parameter in order to detect the fault with its occurrence time. After acquiring the stator current STFT analysis is conducted on current signals and resulting spectrogram will convey the information about the condition of the motor. After analysis of the spectrogram the type and time of the fault can be detected and can be further decided whether motor should continue running or it may be stopped for necessary maintenance.

This section presents the Mathematical model of the induction motor including its simulation and describes STFT analysis in the following sub-sections.

\subsection{MATHEMATICAL MODEL OF THE INDUCTION MOTOR}

The three-phase induction motor model is realized in Simulink using famous dq model that is explained in Simion, Livadaru, and Munteanu (2012), Robyns et al. (2012), and Batool and Ahmad (2013). According to this model the three phase quantities are converted to two phase dq model. The three phases, $120^{\circ}$ electrically apart are converted into two phase voltage i.e. "d" and "q" as shown in Figure 4. The following assumptions are made while considering the two phase dq model: 
- Uniform air gap with no saturation

- Stator windings are distributed sinusoidal.

- Inter bar current is zero

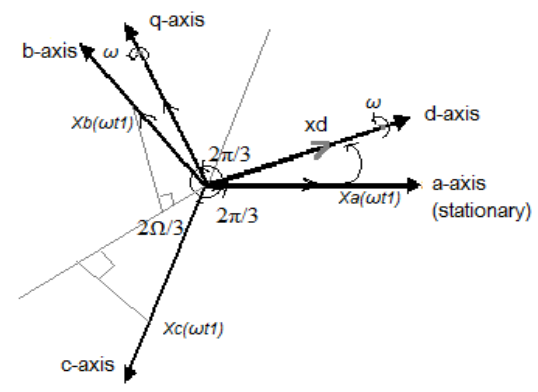

Figure 4. 'abc' to 'dq' conversion.

The equivalent circuit of three phase induction motor is given in Figure 5 with two phases $\mathrm{d}$ and $\mathrm{q}$. All the related parameters are shown with labeling.
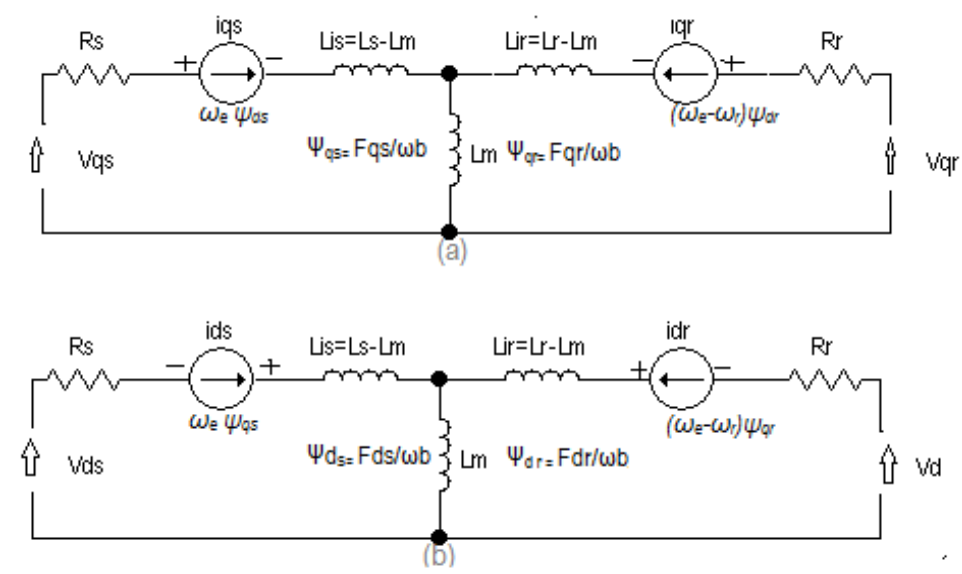

Figure 5. Induction Motor Equivalent circuit.

The following equations can be drawn from the equivalent circuit in order to develop a mathematical model in the Simulink.

$$
\frac{d F q s}{d t}=W_{b}\left[V q s-\frac{W e}{W b} F d s+\frac{R s}{X l s}(F m q+F q s)\right]
$$




$$
\begin{gathered}
\frac{d F d s}{d t}=W_{b}\left[V d s+\frac{W e}{W b} F q s+\frac{R s}{X l s}(F m d+F d s)\right] \\
\frac{d F q s}{d t}=W_{b}\left[V q s-\frac{W e}{W b} F d s+\frac{R s}{X l s}(F m q+F q s)\right] \\
\frac{d F d r}{d t}=W_{b}\left[V d r+\frac{(W e-W r)}{W b} F q r+\frac{R r}{X l r}(F m d-F d r)\right] \\
T e=\frac{3}{2}\left(\frac{P}{2}\right) \frac{1}{W b}\left(F d s * i q s-F q s^{*} i d s\right) \\
T_{e}-T_{L}=J\left(\frac{2}{P}\right) \frac{d W_{r}}{d t}
\end{gathered}
$$

where, $d$ : direct axis, $\quad q$ : quadrature axis, $s:$ stator variable, $r:$ rotor variable, $F i j$ is the flux linkage ( $\mathrm{i}=\mathrm{q}$ or $\mathrm{d}$ and $\mathrm{j}=\mathrm{s}$ or $\mathrm{r}$ ), $v q s, v d s: \mathrm{q}$ and $\mathrm{d}-$-axis stator voltages, $v q r, v d r: \mathrm{q}$ and $\mathrm{d}-$ axis rotor voltages, Fmq, Fmd: q and d axis magnetizing flux linkages, $R r$ : rotor resistance, $R s:$ stator resistance, $X l s$ : stator leakage reactance $\left(w_{e} L l s\right), X l r$ : rotor leakage reactance $\left(w_{e} L l r\right)$

$$
X m l: \frac{1}{\frac{1}{x m}+\frac{1}{x l s}+\frac{1}{x l r}}
$$

iqs, ids : $\mathrm{q}$ and $\mathrm{d}$-axis stator currents,

$i q r, i d r: \mathrm{q}$ and $\mathrm{d}$-axis rotor currents,

$P$ : number of poles,

f : moment of inertia,

$T e:$ electrical output torque,

$T_{L}:$ load torque,

we : stator angular electrical frequency,

$w b$ : motor angular electrical base frequency,

wr : rotor angular electrical speed. 
Figure 6 represents Motor model developed by exploring Simulink Library using equations 03 to 08 (Ozpineci \& Tolbert, 2003; Leedy, 2013). Three phases to two phase voltages are converted by abc-sync block and syn-abc block performs vice versa function. There are two inputs to the motor and three outputs. The inputs are three phase supply and the applied load. The outputs are three phase current, rotor speed and motor output torque.

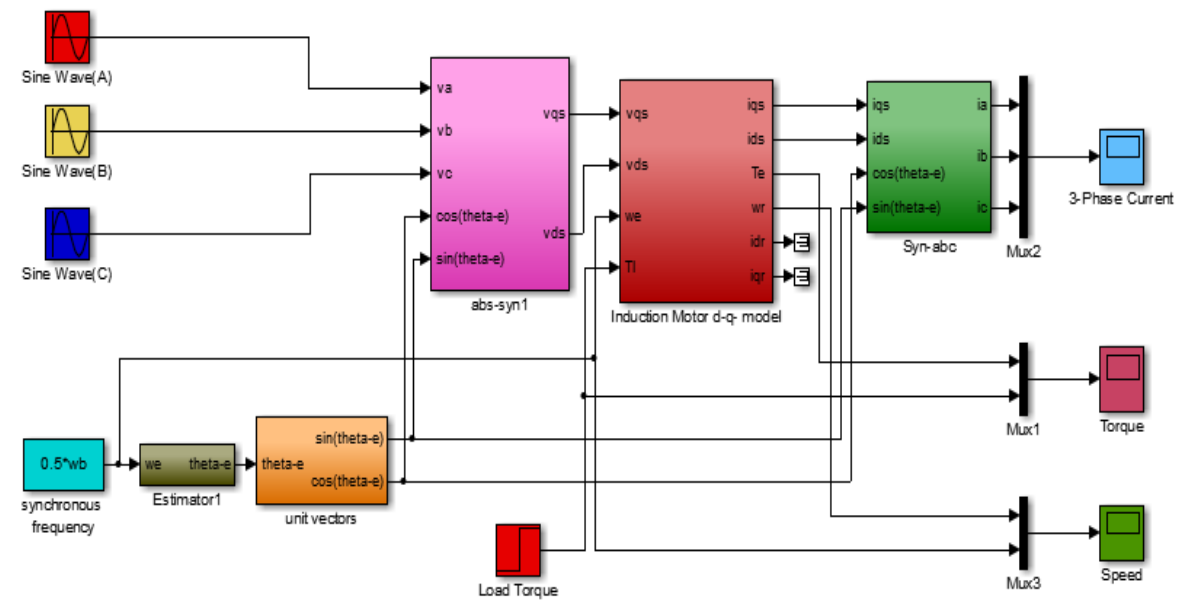

Figure 6. System Model in Matlab.

\subsection{SHORT TIME FOURIER TRANSFORM}

The STFT overcomes the drawback associated with the Fast Fourier Transform. The FFT performs the function of transformation from time to frequency domain. Usually the transformation is performed to extract the additional information from the signal. FFT is converting the signal from time to frequency completely misses out the time information (Polikar, 1994). In case of induction motor faults, the time information is important because some faults are severe and are not required to persist for long time. While there is some irregular behavior or any incipient fault which usually can be tolerated for certain time and the motor does not require the urgent maintenance. FFT fails to provide time information along with frequency information. By using STFT the simultaneous time and frequency information can be obtained. So, with time-frequency results both type and time of the fault can be identified. Mathematically STFT is expressed below: 


$$
\{x(t)\}(\tau, \omega)=X(\tau, \omega) \int_{-\infty}^{\infty} x(t) \omega(t-\tau) e^{-i w t} d t
$$

where, $\mathrm{X}(\tau, \omega)$ is STFT output, $\mathrm{x}(\mathrm{t})$ is input signal, $\mathrm{w}(\tau)$ is the window function

The window function localizes the frequency contents in time. A window function " $w$ " has a tapering at its end to avoid unnatural irregularities present in the signal frequency contents. The window function is the trade-off between time and frequency. The time and frequency information depend upon the size and type of the window. Larger time window will result poor time resolution and vice versa.

Although there are different types of window that are used to localize time frequency representation, but Hamming, Hann and rectangular window are the most popular. In this research work Hamming window is used which resulted the useful information.

\section{RESULTS AND DISCUSSIONS}

This section presents the results obtained from mathematical model of the induction motor. Moreover, it describes each fault introduced in the model and their comparative analysis in terms of FFT and STFT spectrum. The system design, development and simulations are performed in MATALB/Simulink. The motor dq-model is implemented in Simulink and STFT is applied by exporting the parameters in command window. The supply to the motor is $220 \mathrm{~V}, 3$-Phase, $50 \mathrm{~Hz}$. The step function is used as load at different instants. The motor outputs include three phase current, Torque and speed of the rotor.

\subsection{HEALTHY MOTOR CONDITION}

Figures 7 to 9 give motor output parameters in healthy condition. The motor takes high starting current and then have normal current but when a load of $25 \mathrm{~N} / \mathrm{m}$ is applied at 1 second the current is increased while rotor speed is decreased. 


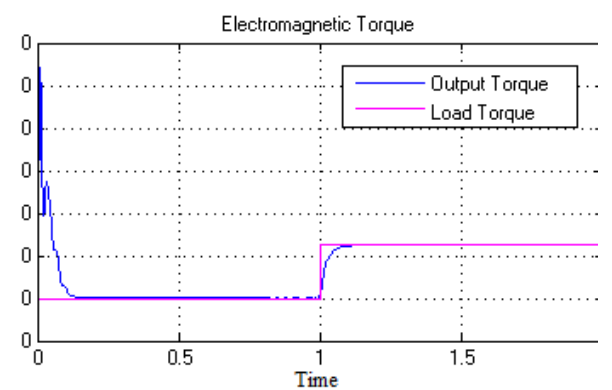

Figure 7. Motor output Torque.

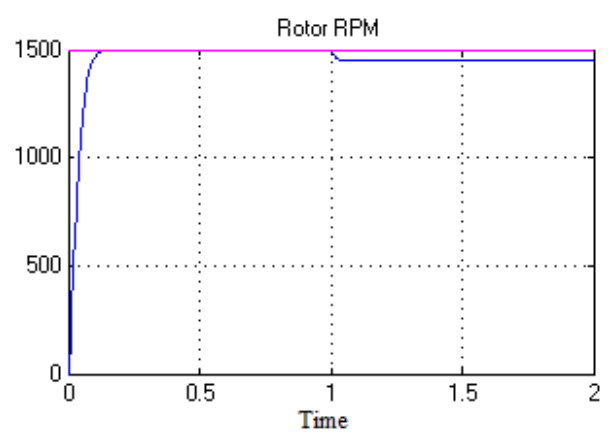

Figure 9. Motor RPM.

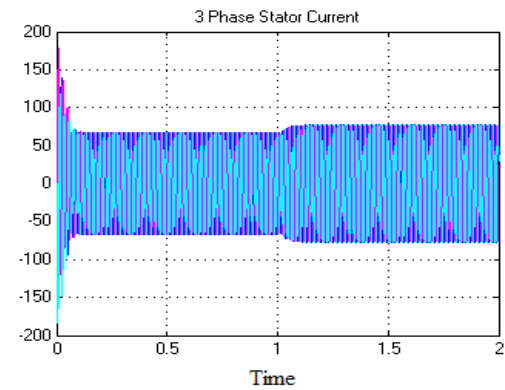

Figure 8. Three phase stator current.

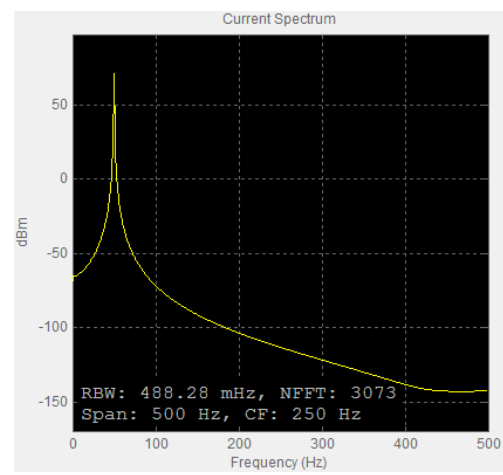

Figure 10. FFT Spectrum.

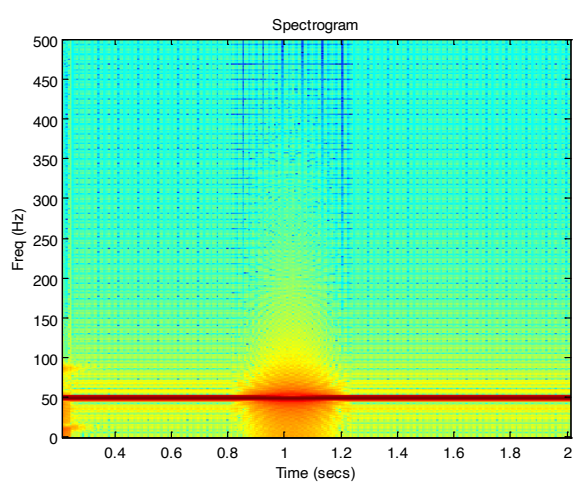

Figure 11. STFT showing abnormality at 1 second.

By taking FFT of stator current, the spectral contents can be seen at $50 \mathrm{~Hz}$ fundamental component which is the indication of healthy motor in Figure 10, FFT can compute perfect spectral contents but it fails to provide time information in addition to frequency information. To observe frequency and time simultaneously the STFT is computed as shown in Figure 11. Figure 11 shows changes at 1 second which is due to the change in 
magnitude (load change) from lower to higher level which we are unable to identify using FFT. By having time domain signal, we can identify the time of any irregularity or event and in order to check that irregularity FFT can be computed but to explore simultaneous Time-Frequency information STFT can be the optimal choice.

\subsection{FAULT 01 SIMULATION: POWER SUPPLY IMBALANCE}

The 20 volts drop is simulated in Red Phase as power supply imbalance fault after 1 second and motor is simulated for 2 seconds which can be seen in time domain in Figure 12, having two irregularities, first at 0.5 second and second at 1 second. In order to check whether it is due to change in load or it is because of any fault, FFT is computed. The FFT shows a sideband is generated at $150 \mathrm{~Hz}$ in Figure 13, which indicates power supply imbalance fault as equation 1 but unable to determine when it occurred. In other words FFT fails to detect nonstationary condition of the signal. While computing STFT Figure 14, show a change in the load at $0.5 \mathrm{sec}$ and a sideband is generated along with main frequency component at $1 \mathrm{sec}$. The color of the sideband generated is light because of the low magnitude of 150 $\mathrm{Hz}$ component.

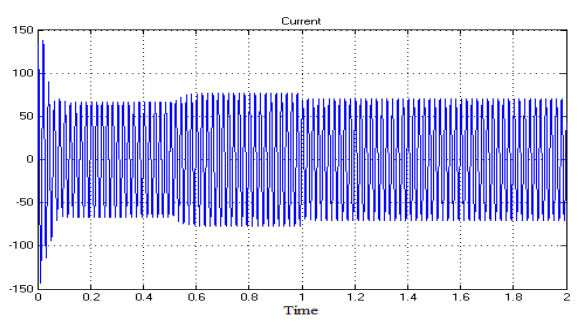

Figure 12. Sideband generated at $150 \mathrm{~Hz}$.

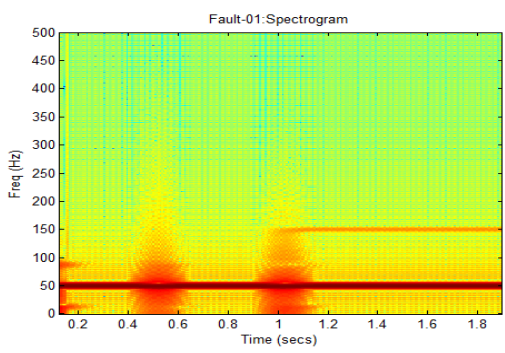

Figure 14. Power supply imbalance spectrogram.

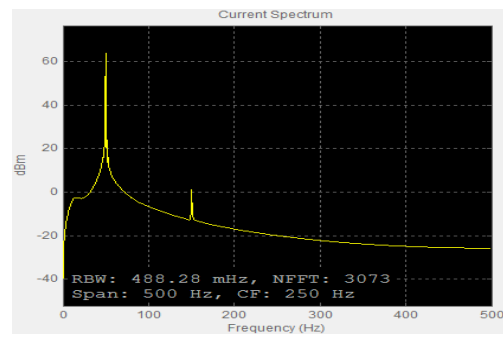

Figure 13. 20 Volt drop introduced after 1 second.

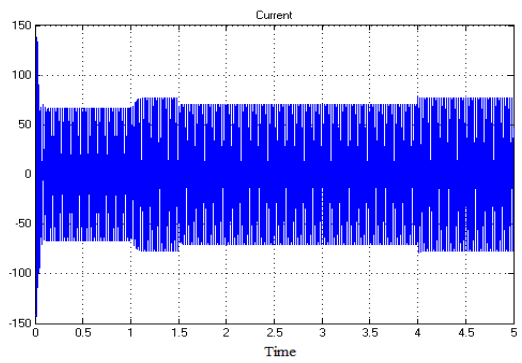

Figure 15. 20V drop between 1.5 to 4 seconds. 
Again, the same 20 Volt drop in Red Phase is simulated between 1.5 to 4 seconds and can be seen in Figure 15, that time domain representation is unable to convey the information about irregularities at $1 \mathrm{sec}, 1.5 \mathrm{sec}$ and at 4 second. Computing FFT of red phase for same $20 \mathrm{~V}$ drop shown in Fig. 16 that a sideband is generated at $150 \mathrm{~Hz}$ frequency which is the indication of power supply imbalance fault but again we are unaware what happened at $1 \mathrm{sec}, 1.5 \mathrm{sec}$ and at $4 \mathrm{sec}$ instants. By analyzing the same fault by STFT Fig. 17, gives some idea about the time of load change and type of fault by looking $150 \mathrm{~Hz}$ sideband between 1.5 to 4 seconds.

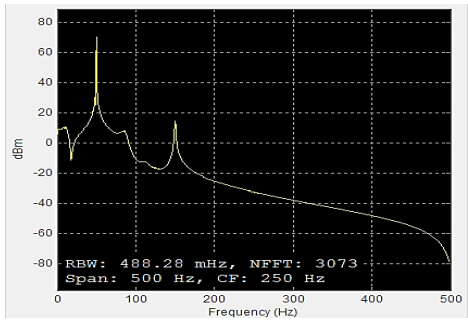

Figure 16. FFT for $20 \mathrm{~V}$ drop between 1,5 to 4 seconds. Figure 17. STFT for $20 \mathrm{~V}$ drop between 1.5 to 4 seconds.

Figure 18 shows the 3-D spectrogram of the single fault i.e. imbalance in the supply phase voltages. It is showing all three parameters time frequency and magnitude of the signal, describing health and faulty portion of the signal. Similarly in Figure 19, power supply imbalance fault is detected between 01 to 03 seconds at no load condition.

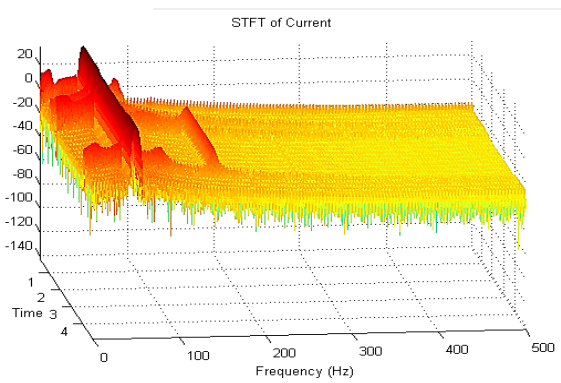

Figure 18. 3D spectrogram for imbalance of supply Figure 19. STFT for power imbalance fault between 1 voltage.

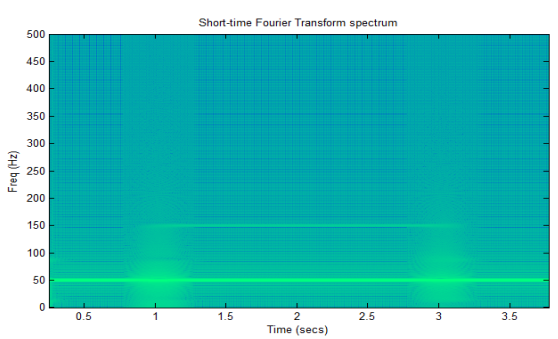

to 3 seconds.

\subsection{FAULT 02 SIMULATION: SINGLE PHASING CONDITION}

Single phasing occurs if any phase among three phases of the supply is missing. Due to this condition current among the two phases increses drastically and can cause permenant 
damage to induction motor. As in Figure 20, load is applied after 1 sec and single phasing is introduced at $2 \mathrm{sec}$ that causes huge increase in current. If in this condition motor is allowed to run it may be permenantly damaged. By looking at Time domain reprsentation we can not estimate what happened at '01' and '02' second. By computing FFT of the current signal in Figure 21 sidebands at 150,250 and $350 \mathrm{~Hz}$ are generated that is the clear indicatoin of single phasing condition according to relation (1). For having simultaneous time frequency information STFT is computed as shown in Figure 22, showing three side bands after 2 seconds. It is clear from Figure 22 that $50 \mathrm{~Hz}$ fundamental is dominant while 150,250 and $350 \mathrm{~Hz}$ has respectively decreasing contribution. Figure 23 shows 3D spectrogram for single phasing condition.

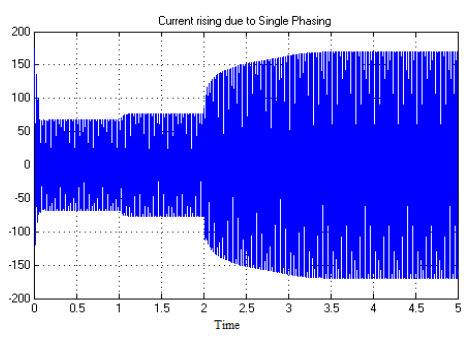

Figure 20. Irregularity at 1 and 2 seconds.

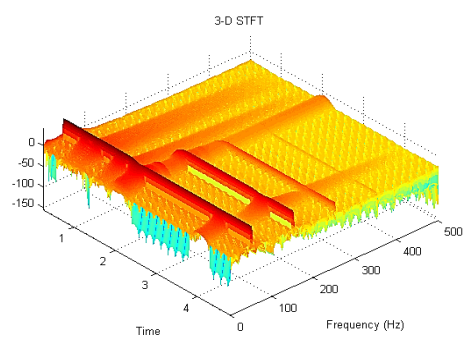

Figure 22. 3D Spectrogram for Figure 20.

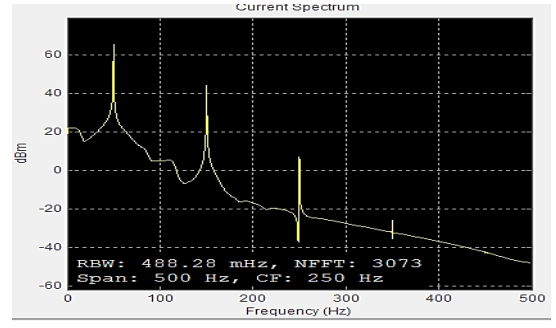

Figure 21. FFT for irregualrity at 1 and 2 sec.

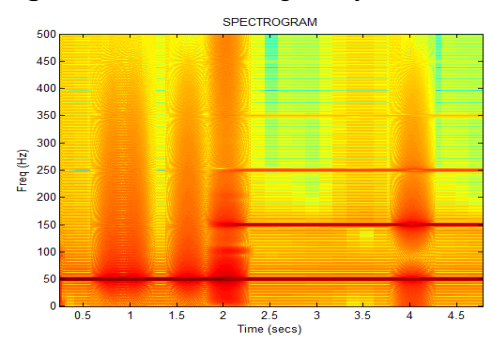

Figure 23. Irregualrity identified by STFT.

\subsection{FAULT 03: BROKEN ROTOR BAR DETECTION}

Figures 24-26 showing the diagrams for broken rotor bar fault in time, frequency and timefrequency domain respectively. The broken rotor bar fault is introduced by changing the resistance of the rotor circuit. Due to broken rotor bar two sidebands are generated at 36 $\mathrm{Hz}$ and $64 \mathrm{~Hz}$ according to equation (2). Figure 25 shows both sidebands are present for all times along with main frequency component. So broken rotor bar fault is present since start and remains all the time. 


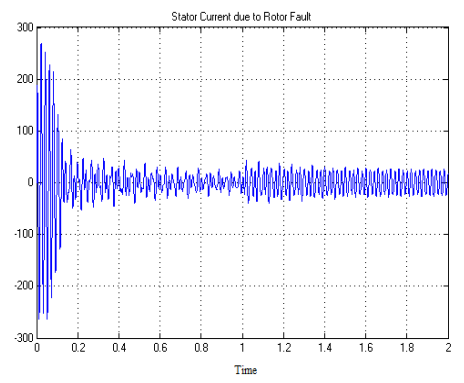

Figure 24. Broken rotor bar fault in time domain.

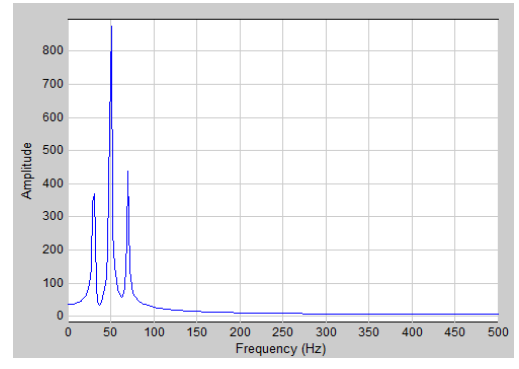

Figure 25. Broken rotor bar fault in frequency domain.

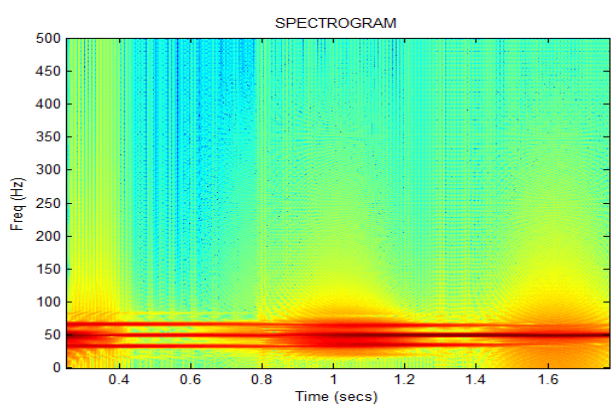

Figure 26. Broken rotor bar fault in time and frequency domsain.

\subsection{MULTIPLE FAULT INDUCTION}

When multiple faults are present in the motor then it is necessary to find out their occurrence time in order to know the nature of the fault so that it can be decided whether motor should continue to run, or it may be stopped. Figure 27 shows FFT spectrum for broken rotor bars and power supply imbalance faults together. Three side bands along with $50 \mathrm{~Hz}$ frequency component are generated. Two sidebands at $36 \mathrm{~Hz}$ and $64 \mathrm{~Hz}$ are due to the result of two broken bars and one sideband at $150 \mathrm{~Hz}$ frequency is the result of power supply imbalance fault but the time information of these faults is missing. Figure 28 shows the computation of STFT for these two faults. It is clear from the spectrogram that broken rotor bar fault is present all the time while power supply imbalance fault has occurred at 1.5 second instant. Similarly Figures 29 and 30 shows the six broken bars and power supply imbalance faults. Broken bar fault is present all the time and power supply imbalance fault exist between 1 to 3 seconds. 


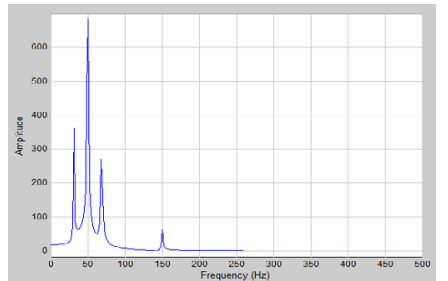

Figure 27. Two Broken Bars and Power Supply imbalance faults together.

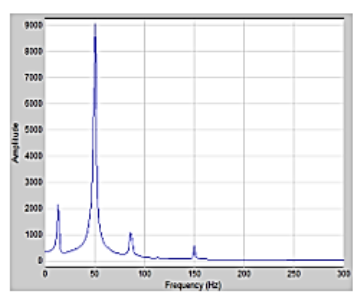

Figure 29. Six broken bars and $20 \mathrm{~V}$ drop fault.

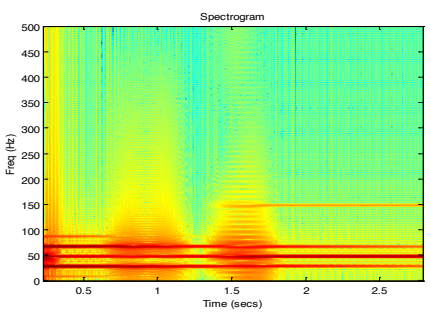

Figure 28. Spectrogram for Broken Bar and Power Supply imbalance faults together.

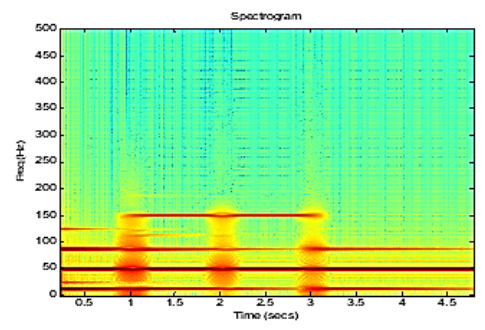

Figure 30. STFT for Six broken bars and $20 \mathrm{~V}$ drop fault.

\section{CONCLUSION}

Previously, a lot of research has been conducted on Induction motor fault diagnoses for single fault detection using multiple signal processing techniques. Very less work is reported on simultaneous multiple faults detection. In this paper, multiple faults with time information are successfully diagnosed in induction motor. Monitoring system efficiently detected imbalance of supply, single phasing and broken rotor bars occurring at different instants of time. This study can help to overcome the drawback of techniques which are unable to provide simultaneous time-frequency information of multiple faults. The short time Fourier transforms has accurately provided the desired results for multiple faults with their occurrence time. For more detailed information of the faults WT is better choice but for ordinary faults STFT provides optimal results and conveys enough time-frequency information with lesser efforts. In case of wavelet transform more calculations are required because of complex nature. By incorporating this research in the industries and agriculture fields, online health of the machine can be monitored. Upon having the knowledge of time and type of faults desired maintenance strategy can be applied thus saving enough time by avoiding costly downtime. 


\section{ACKNOWLEDGMENT}

The authors express their gratitude to Higher Education Commission (HEC), Pakistan and Ministry of planning and development Pakistan for providing funds for this research work as national laboratory on 'Haptics and Human-Robotic, Condition Monitoring Systems Lab. This lab is part of the National Center of Robotics and Automation (NCRA). We are also thankful to MUET Jamshoro for providing lab facility to perform research work.

\section{REFERENCES}

Batool, M., \& Ahmad, A. (2013). Mathematical modeling and speed torque analysis of three phase squirrel cage induction motor using matlab simulink for electrical machines laboratory. International Electrical Engineering fournal (IEEf), 4(1), 880-889. https://tarjomefa.com/wp-content/uploads/2016/09/5246-English.pdf

Benbouzid, M. E. H. (2000). A review of induction motors signature analysis as a medium for faults detection. IEEE Transactions on Industrial Electronics, 47(5), 984-993. https:// ieeexplore.ieee.org/document/873206

Çalış, H., \& Çakır, A. (2008). Experimental study for sensorless broken bar detection in induction motors. Fournal of Energy Conversion \& Management, 49(4), 854-862. https:// doi.org/10.1016/j.enconman.2007.06.030

Gusidó, J., Romeral, L., Ortega, J. A., Rosero, J. A., \& Espinosa, A. G. (2008). Fault detection in induction machines using power spectral density in wavelet decomposition. IEEE Transactions on Industrial Electronics, 55(2), 633-643. https://doi. org/10.1109/TIE.2007.911960

Da Silva, A. M., Povinelli, R. J., \& Demerdash, N. A. (2008). Induction machine broken bar and stator short-circuit fault diagnostics based on three-phase stator current envelopes. IEEE Transactions on Industrial Electronics, 55(3), 1310-1318. https: / / doi.org/10.1109/TIE.2007.909060 
El Bouchikhi, E. H., Ghoqueuse, V., \& Benbouzid, M. (2015). Induction machine diagnosis using stator current advanced signal processing. International fournal on Energy Conversion, 3(3), 76-87. https://hal.archives-ouvertes.fr/hal-01249256/document

Gao, Z., Gecati, G., \& Ding, S. X. (2015). A survey of fault diagnosis and fault-tolerant techniques - Part I: Fault diagnosis with model-based and signal-based approaches. IEEE Transactions on Industrial Electronics, 62(6), 3757-3767. https://doi.org/10.1109/ TIE.2015.2417501

Haggag, S., \& Mageed, H. M. A. (2013). A new fault detection tool for single phasing of a three phase induction motor. Proceedings of the World Congress on Engineering 2013, Vol II, WCE 2013, July 3 - 5, 2013, London, U.K. https://www.researchgate.net/ publication/289698804_A_New_Fault_Detection_Tool_for_Single_Phasing_of_a_ Three_Phase_Induction_Motor

Lee, G.-Y. (1999). Effects of unbalanced voltage on the operation performance of a threephase induction motor. IEEE Transactions on Energy Conversion, 14(2), 202-208. https:/ / doi.org/10.1109/60.766984

Leedy,A.W.(2013). Simulink/matlabdynamicinductionmotormodelforuseasatteachingand research tool. International fournal of Soft Computing and Engineering (IFSCE), 3(4), 102-107. https:/ /pdfs.semanticscholar.org/8005/18f68fac0e276d4b7be0ad0896e39d6714ee. pdf

Liang, B., Payne, B. S., Ball, A. D., \& Iwnicki, S. D. (2002). Simulation and fault detection of three-phase induction motors. Fournal of Mathmatics and Computers in Simulation, 61(1), 1-15. https://doi.org/10.1016/S0378-4754(02)00064-2

Mal, K., Hussain, I., Chowdhry, B. S., \& Memon, T. D. (2020). Extended kalman filter for estimation of contact forces at wheel-rail interface. 3C Tecnología. Glosas de innovación aplicadas a la pyme. Edición Especial, Abril 2020, 279-301. http://doi. org/10.17993/3ctecno.2020.specialissue5.279-301 
Mehala, N., \& Dahiya, R. (2008). A comparative study of FFT, STFT and wavelet techniques for induction machine fault diagnostic analysis. Proceedings of the 7th WSEAS International Conference on COMPUTATIONAL INTELLIGENCE, MAN-MACHINE SYSTEMS and CYBERNETICS (CIMMACS ,08). http://www.wseas.us/e-library/ conferences/2008/cairo/CD-CIMMACS/CIMMACS34.pdf

Mehrjou, M. R., Mariun, N., Marhaban, M. H., \& Misron, N. (2010). Evaluation of fourier and wavelet analysis for efficient recognition of broken rotor bar in squirrelcage induction machine. In 2010 IEEE International Conference on Power and Energy, Kuala Lumpur, Malaysia. https://doi.org/10.1109/PECON.2010.5697678

Messaoudi, M., \& Sbita, L. (2010). Multiple faults diagnosis in induction motor using the mcsa method. International Journal of Signal \& Processing, 1(3), 190-195. https:// www.academia.edu/31924332/Multiple_Faults_Diagnosis_in_Induction_Motor_ Using_the_MCSA_Method

Mirabbasi, D., Seifossadat, G., \& Heidari, M. (2009). Effect of unbalanced voltage on operation of induction motors and its detection. In 2009 International Conference on Electrical and Electronics Engineering - ELECO 2009, Bursa, Turkey. https://doi. org/10.1109/ELECO.2009.5355288

Mortazavizadeh, S., \& Mousavi, S. (2014). A review on condition monitoring and diagnostic techniques of rotating electrical machines. Physical Science International Fournal, 4(3), 310. https://doi.org/10.9734/PSIJ/2014/4837

Nandi, S., Toliyat, H. A., \& Li, X. (2005). Condition monitoring and fault diagnosis of electrical motors - A review. IEEE Transactions on Energy Conversion, 20(4), 719-729. https://doi.org/10.1109/TEG.2005.847955

Ozpineci, B., \& Tolbert, L. M. (2003). Simulink implementation of induction machine model-a modular approach. In IEEE International Electric Machines and Drives Conference, 2003. IEMDC'03, Madison, WI, USA, USA. https://doi.org/10.1109/ IEMDG.2003.1210317 
Pandey, K., Zope, P., \& Suralkar, S. (2012). Review on fault diagnosis in three-phase induction motor. In MEDHA-2012, Proceedings published by International fournal of Computer Applications (IFCA). https://www.ijcaonline.org/proceedings/medha/ number1/8680-1024

Polikar, R. (1994). The wavelet tutorial (2nd ed.). Part I.

Quispe, E., Gonzalez, G., \& Aguado, J. (2004). Influence of unbalanced and waveform voltage on the performance characteristics of three-phase induction motors. In International Conference on Renewable Energies and Power Quality, Barcelona. http://www. icrepq.com/PONENCIAS/4.279.QUISPE.pdf

Robyns, B., Francois, B., Degobert, P., \& Hautier, J. P. (2012). Vector control of induction machines. In Vector control of induction machines (pp. 75-121). Springer.

Sharma, A., Chatterji, S., Mathew, L., \& Khan, M. J. (2015). A Review of Fault Diagnostic and Monitoring Schemes of Induction Motors. International Fournal for Research in Applied Science and Engineering Technology (IFRASET), 3(4). http:/ /behpouyan. ir/uploads/maghalat/861--57930db2-856c-47f1-bcf6-3453b9041dc8.PDF

Shi, P., Chen, Z., Vagapov, Y., Davydova, A., \& Lupin, S. (2014). Broken bar fault diagnosis for induction machines under load variation condition using discrete wavelet transform. Proceedings of IEEE East-West Design \& Test Symposium (EWDTS 2014), Kiev, Ukraine. https://doi.org/10.1109/EWDTS.2014.7027059

Siddiqui, K. M., \& Giri, V. (2012). Broken rotor bar fault detection in induction motors using wavelet transform. In 2012 International Conference on Computing, Electronics and Electrical Technologies (ICCEET), Kumaracoil, India. https://doi.org/10.1109/ ICGEET.2012.6203753

Siddiqui, K. M., Sahay, K., \& Giri, V. (2014). Health monitoring and fault diagnosis in induction motor-a review. International Fournal of Advanced Research in Electrical, Electronics and Instrumentation Engineering, 3(1), 6549-6565. https://www.semanticscholar.org/ paper/Health-Monitoring-and-Fault-Diagnosis-in-Induction-Siddiqui-Sahay/678e 583567bce8a74397ab26ee677f3afc4d41bc 
Simion, A., Livadaru, L., \& Munteanu, A. (2012). Mathematical model of the three-phase induction machine for the study of steady-state and transient duty under balanced and unbalanced states. https://doi.org/10.5772/49983

Soother, D. K., \& Daudpoto,J. (2019). A brief review of condition monitoring techniques for the induction motor. Transactions of the Canadian Society for Mechanical Engineering, 43(4), 499-508. https:/ /doi.org/10.1139/tcsme-2018-0234

Soother, D. K., Daudpoto, J., \& Shaikh, A. (2018). Vibration measurement system for the low power induction motor. Engineering Science And Technology International Research Fournal, 2(4), 53-57. https://www.researchgate.net/publication/332672765_ Vibration_measurement_system_for_the_low_power_induction_motor

Szabó, L., Dobai, J. B., \& Biró, K. A. (2004). Rotor faults detection in squirrel-cage induction motors by current signature analysis. Proceedings of the 2004 IEEE-TTTC - International Conference on Automation, Quality and Testing, Robotics, A\&QTR 2004 (THETA 14), Cluj (Romania), Tome I., pp. 353-358. https://www.academia. edu/20689627/Rotor_Faults_Detection_in_Squirrel_Cage_Induction_Motors_ by_Current_Signature_Analysis

Ujjan, S. M., Kalwar, I. H., Chowdhry, B. S., Memon, T. D., \& Soother, D. K. (2020). Adhesion level identification in wheel-rail contact using deep neural networks. $3 C$ Tecnología. Glosas de innovación aplicadas a la pyme. Edición Especial, Abril 2020, 217-231. http://doi.org/10.17993/3ctecno.2020.specialissue5.217-231

Zhongming, Y., \& Bin, W. (2000). A review on induction motor online fault diagnosis. Proceedings IPEMC 2000. Third International Power Electronics and Motion Control Conference (IEEE Cat. No.00EX435), Beïing, China, China. http://doi.org/10.1109/ IPEMG.2000.883050 
3C Tecnología. Glosas de innovación aplicadas a la pyme. ISSN: 2254 - 4143 Edición Especial Special Issue Noviembre 2020 